Journal of Reproduction and Development, Vol. 39, No. 3, 1993

\title{
The Effects of the Nucleocytoplasmic Ratio and the State of Nuclear and Cytoplasmic Differentiation on the Development of Cloned and Recloned Embryos of Mice
}

\author{
Li MENG* and Clement L. MARKERT \\ Department of Animal Science, North Carolina \\ State University, Raleigh, NC 27695 U.S.A
}

\begin{abstract}
Nucleocytoplasmic interactions in controlling mouse embryonic development were tested by transplanting nuclei into different cytoplasmic environments. The nucleocytoplasmic ratios in 2and 4-cell stage embryo were altered by removing one nucleus from a fused 2-cell and three nuclei from a fused 4-cell embryo. Such embryos containing relatively increased amounts of cytoplasm develop normally but at a slower rate than control embryos.

The effects of transplanting 4-cell donor nuclei to the cytoplasm of an enucleated fused 2-cell embryo led to successful in vitro development and also to term in six out of 67 reconstituted embryos. When the donor nucleus was from an 8-cell embryo, successful development in vitro was less frequent and none were carried to term. Cytoplasms from the 2-cell and 4-cell embryos were very similar in affecting further development, but cytoplasms of the oocyte failed to provide a suitable environment for further development. Most of the reconstituted embryos containing a nucleus from an 8-cell embryo and cytoplasms of 2 or 4 -cell embryos compacted at the subsequent 4 cell or even at the 2-cell stage of development. Thus, an 8-cell nucleus produced compaction in cytoplasms from an earlier stage.

To test for reprogramming of nuclei transferred into the cytoplasms of an earlier stage of development, the nuclei from 4-cell stage reconstituted embryos were transferred into the cytoplasms of 2-cell embryos. Of the 53 recloned embryos $36(67.9 \%), 15$ (28.3\%), and 1 (1.7\%) developed to the 2-, 4-, and 8-cell stages, respectively. The percent cleavage of recloned 4-cell stage nuclei was much lower than in the original reconstituted embryos. However no significant difference in frequency of cleavage was found between recloned embryos and reconstituted embryos with nuclei obtained from the normal morula stage. Forty-one of the recloned embryos were transferred to the oviducts of recipient mice. Of these, 17 were recovered from the oviducts after $72 \mathrm{~h}$ and five then continued to develop in vitro to the morula stage. These results suggest that embryonic nuclei are not reprogrammed, even by retransfer into less differentiated cytoplasms obtained from enucleated, fused 2-cell embryos.

Key words: Nuclear transplantation, Cloning, Nuclear-cytoplasmic interaction, Nucleocytoplasmic ratio, Mouse embryo.
\end{abstract}

(J. Reprod. Dev. 39: 175-185, 1993)

$\mathbf{N}$ uclear transplantation has proved successful in some mammalian species. One result of the transplantation of a single nucleus from a late

Accepted for Publication: February 18, 1993

Correspondence: L. Meng

*Present address: Reproductive Biology Research Laboratories, Department of Obstetrics \& Gynaecology, The University of Western Ontario, 339 Windermere Road, London, Ontario, Canada N6A 5A5 many-celled embryo into an early enucleated cytoplasm is that both the nucleocytoplasmic ratio and the relative maturation states of nucleus and cytoplasm have been changed in the reconstituted embryos. One reason for failure of development after nuclear transplantation may be due to the asynchrony of cytoplasm and nucleus.

In experiments on nuclear transplantation in fish [1] and amphibia [2], the cytoplasm content of 
cells was halved and the nucleocytoplasmic ratio increased after DNA replication and subsequent cytokinesis. The cytoplasm was distributed into the resulting blastomeres until a critical nucleocytoplasmic ratio was attained. As in fish and amphibia, the nucleocytoplasmic ratio may also influence embryo development in mice. Petzoldt and Muggleton-Harris [3] found that an experimental increase of the nucleocytoplasmic ratio by bisecting two-cell and four-cell stage embryos (with a doubling of the nucleocytoplasm ratio) did not change the protein content as compared to the control embryos at the same stage of development. These authors noted that stage-specific gene expression is independent of the nucleocytoplasmic ratio. However, the formation of a male pronucleus is accelerated when the volume of the cytoplasm of the oocyte is decreased so as to increase the nucleocytoplasmic ratio [4]. Also the development of haploid embryos is improved by reducing the volume of cytoplasm [5]. Furthermore, with a decrease in the nucleocytoplasmic ratio blastomere with a doubled content of cytoplasm [6], the time required to form blastocyst cavities in the reconstituted embryo was delayed $12 \mathrm{~h}$. Even though the rate of cell division did not change, this delay in the triggering of cavitation in the reconstituted embryos has been presented as evidence for genomic reprograming $[7,8]$. Thus the nucleocytoplasmic ratio does seem to influence significantly the development of the early mammalian embryo.

On the other hand, when an 8-cell nucleus was introduced into an enucleated zygote, the reconstituted embryo expressed heat shock proteins $(h s p)$, that are characteristic of the first activity of the embryonic genome [9, 10]. These results showed that in reconstituted embryos a normal zygote-totwo-cell transition in the type of polypeptides synthesized occurred; moreover, $\left[{ }^{35} \mathrm{~S}\right]$ methionine uptake reached a level equivalent to that in a normal two-cell embryo. In contrast, in reconstituted embryos, in which 2-cell cytoplasm received an 8-cell nucleus, the $68 \times 10^{3} \mathrm{M}_{\mathrm{r}}(h s p)$ was found to persist and then was weakly expressed. But the $70 \times 10^{3} \mathrm{M}_{\mathrm{r}}(h s p)$ was diminished and soon disappeared at the same time a protein complex $\left(66 / 44 \times 10^{3} \quad M_{r}\right) \quad$ with enhanced expression appeared. This increased synthesis occurred earlier in the reconstituted embryos than in the comparable control embryos. The donor 8-cell nuclei directed normal $\left[{ }^{35} \mathrm{~S}\right]$ methionine uptake in the recipient 2-cell cytoplasms. These donor nuclei showed no nuclear swelling [11] as might have been expected if reprogramming had occurred. However, 8-cell nuclei in the 2-cell cytoplasm did show significantly higher developmental abilities than in the cytoplasm of the zygote [12] and even developed to term $[13,14]$. These results demonstrated that the relative nucleocytoplasmic states of maturation are quite crucial for the development of embryos after nuclear transplantation. Thus, for successful development of embryos to occur after nuclear transplantation, functional compatibility between the donor nucleus and the recipient cytoplasm is essential.

In the present investigation, we attempted to investigate the roles of the nucleocytoplasmic ratio and the maturation state of nucleus and cytoplasm on the early development of cloned and recloned mouse embryos. The first objective has been to determine the influence of the decrease in the nucleocytoplasmic ratio on the development of early embryos. Next, experiments were carried out to examine the interaction of nucleus and cytoplasm at different relative states of maturation. Three different approaches were used. In the first, the same stage donor nuclei were introduced into different cytoplasmic environments. In the second, different stage nuclei were implanted into the same stage of cytoplasmic maturity. In the third, nuclei in the initial stage of interphase were implanted into the enucleated fused cytoplasm of the final stage of the last interphase. This procedure shortened the "gap" in development between the donor nucleus and the recipient cytoplasm in order to improve their functional compatibility. The final objective has been to increase the time available for nucleocytoplasmic interaction by performing serial transfers of nuclei from 4-cell embryos. Thus recloning nuclei from already cloned embryos permitted extensive multiplication of nuclei in cytoplasms of essentially the same stage of differentiation. The time available for reprogramming nuclei was therefore increased.

\section{Materials and Methods}

\section{Preparation of recipient oocytes and embryos}

Three- to six-week-old albino CD-1 mice served as donors for oocytes, 2-cell, and 4-cell embryos. They were superovulated by injection of $5 \mathrm{IU}$ 
pregnant mares' serum gonadotrophin (PMSG; SIGMA) and 5 IU human chorionic gonadotrophin (hCG; SIGMA) given $48 \mathrm{~h}$ apart. Oocytes were obtained 17-19 h after hCG injection from the oviduct of superovulated females; the cumulus cells were removed by treatment with hyaluronidase (SIGMA, $300 \mathrm{IU} / \mathrm{ml}$ ) in the medium of Whitten as modified by Anderegg and Markert [15] and then washed several times. The CD-1 females were paired with males of the same strain after the injection. Later, 2-cell and early 4-cell embryos were collected by flushing the oviducts with the culture medium $46-50 \mathrm{~h}$ after hCG injection.

\section{Preparation of donor embryos and isolation of} blastomeres

Seven- to 11-week-old female mice (C57/6J) were superovulated and paired with BDF-1 males. Donor 4-cell, 8-cell, and morula stage embryos were collected by flushing with the culture medium at 50-54, 63-66, and $72 \mathrm{~h}$, respectively. Zonae pellucidae were removed by treatment with culture medium containing $5 \mathrm{mg} / \mathrm{ml}$ pronase (SIGMA) and washed several times in fresh culture medium. The zona-free embryos were placed in $0.25 \%$ trypsin (SIGMA) in a $\mathrm{Ca}^{2+}$ and $\mathrm{Mg}^{2+}$. free medium for approximately $10 \mathrm{~min}$, and individual blastomeres were then isolated by repeatedly pipetting the embryos with a fire-polished pipette.

\section{Electrofusion}

Membrane fusion of the recipient 2-cell and 4-cell embryos was accomplished by the use of electrofusion [16]. The 10-15 nonfused embryos were placed in three drops of cell fusion medium $\left(0.3 \mathrm{M}\right.$ mannitol $+0.1 \mathrm{mM} \mathrm{MgSO}_{4}+0.05 \mathrm{mM}$ $\mathrm{CaCl}_{2}$ ) [17] for a $3 \mathrm{~min}$ equilibration period. Then once for 2-cell embryos, and twice for 4-cell embryos, a $90 \mathrm{~V}, 30 \mu$ sec pulse was applied across a $0.5 \mathrm{~mm}$ gap between electrodes where the recipient embryos were placed. The source of the electrical current was a High Voltage Cell Processor (Model \#1000, Bioelectronics Corporation, Troy, Michigan, U.S.A.). The alignment of the blastomeres is important for cell fusion; the fusion membranes must be parallel to the two electrodes. After electrofusion, the embryos were washed several times.

\section{Micromanipulation and nuclear transplantation}

Micromanipulation was performed as described previously [18, 19]. Embryos were treated with cytochalasin B (SIGMA, $5 \mu \mathrm{g} / \mathrm{ml}$ ) and colcemid (SIGMA, $0.1 \mu \mathrm{g} / \mathrm{ml}$ ) for $10 \mathrm{~min}$ at $37 \mathrm{C}$ prior to the micromanipulation. During micromanipulation the recipient oocytes or fused embryos were placed together with isolated donor blastomeres in the same $50 \mu \mathrm{l}$ culture drop containing cytochalsin $\mathrm{B}$ and colcemid, and covered with paraffin oil. In Experiment 1, the one nucleus of the fused 2-cell embryo and three nuclei of the fused 4-cell embryo were drawn into a 15-20 $\mu$ m enucleation pipette. In Experiment 2, the nuclei were removed from the fused 2-cell or 4-cell embryos during a single microsurgical penetration of the embryo. Enucleation was assessed by identifying the nucleus ( or nuclei) in the pipette. In preparing oocytes for nuclear transplantation about one third of the cytoplasm containing the metaphase II chromosomes located directly below the first polar body was removed. A blastomere was aspirated into the same pipette and placed into the perivitelline space against the enucleated oocyte or fused embryo. The donor nuclei were then introduced into the enucleated recipient cytoplasm by electrofusion as described above.

\section{In vitro culture and monitoring of micromanipu-} lated embryos

After micromanipulation (Experiment 1) and electrofusion (Experiments 2, 3) the embryos were washed several times and placed in $50 \mu \mathrm{l}$ of culture medium covered with paraffin oil, and incubated in a humidified, plastic container at $37 \mathrm{C}$ under an atmosphere of $5 \% \mathrm{CO}_{2}$ in air. In vitro cultured embryos were monitored every $8-12 \mathrm{~h}$ to assess development.

\section{Transfer of micromanipulated embryos}

After electrofusion, some reconstituted embryos (no control embryos) were immediately transferred into the oviducts of synchronized pseudopregnant CD-1 females. The recipients (no hormone was injected) were mated to a CD-1 vasectomized male. Next day, if the plug was found, was counted as day 1 of pseudopregnancy. In Experiment 3, on day 3 after the embryos were transplanted, the recipients were killed, and the transferred embryos were recollected. In Experiment 2, the 
offspring successfully derived from the reconstituted embryos were examined for the color of the eyes and the fur. The statistical significance of the experimental results was examined by the Chisquare test.

\section{Results}

Experiment 1: The developmental abilities of the low nucleo-cytoplasmic ratio embryos in vitro

During this experiment, 2- cell and 4-cell stage mouse embryos were fused individually to make multinucleated syncytia. From these fused 2-cell (Group A) or 4-cell (Group B) embryos one nucleus and three nuclei were removed, respectively, causing these reconstituted embryos to have lower nucleoplasmic ratios than those of normal 2-cell and 4-cell embryos. In Group A, the reconstituted embryos had half the normal nucleocytoplasmic ratio. In Group B, the reconstituted embryos had one fourth the normal nucleocytoplasmic ratio. The development of these reconstituted embryos was monitored in vitro (Table 1). The developmental difference between Group A and Group $B$ is not significant $(P>0.05)$, but the developmental rates of both these two groups of embryos with low nucleocytoplasmic ratios proceeded at a significantly lower rate than did those of the normal control 2-cell and 4-cell stage embryos. This result suggested that an excess of cytoplasm (low nucleocytoplasmic ratio) was in some way detrimental to development in vitro.

The cleavage rate of the reconstituted low nucleocytoplasmic ratio embryos was measured (Table 2). The cleavage rates of these two groups of reconstituted embryos did not show significant differences during $24 \mathrm{~h}$ after micromanipulation $(\mathrm{P}>0.05)$. This fact indicated that the nucleus at the late interphase of the 2-cell stage with double the cytoplasm could extend the interphase stage of the blastomeres. Reconstituted embryos with a late 2-cell nucleus and a doubled amount of cytoplasm require a similar amount of time to finish the first cleavage as do the reconstituted embryos derived from early 4-cell embryos and containing one nucleus and four times the normal amount of cytoplasm per nucleus.

Experiment 2: The effect of the nucleocytoplasmic state of maturation on mouse embryo development

Table 3 records the developmental abilities in vitro of the reconstituted embryos. Enucleated fused 2-cell and 4-cell stage embryos and oocytes at metaphase II provided the cytoplasts to receive advanced embryonic nuclei. The effects of donor nuclei were investigated by transferring nuclei

Table 1. The development of low nucleocytoplasmic ratio reconstituted embryos in vitro

\begin{tabular}{cccccc}
\hline & \multirow{2}{*}{$\begin{array}{c}\text { No. of } \\
\text { Group }\end{array}$} & Eucleocytoplasmic & \multicolumn{2}{c}{ No. (\%) of embryos Developed to } \\
\cline { 4 - 6 } & Embryos & Ratio & 2-Cell (\%) & 4-Cell (\%) & 8-Cell (\%) \\
\hline A $^{*}$ & 60 & $1: 2$ & $48(80.0)$ & $32(53.3)$ & $11(18.3)$ \\
B $^{* *}$ & 57 & $1: 4$ & $56(89.5)$ & $40(70.2)$ & $7(12.3)$ \\
\hline
\end{tabular}

*Fused late 2-cell stage embryos with one nucleus removed.

**Fused early 4-cell stage embryos with three nuclei removed. $\mathrm{P}>0.05$.

Table 2. Cleavage proportions per unit time of reconstituted embryos with low nucleocytoplasmic ratios at $6 \mathrm{~h}$ intervals after micromanipulation.

\begin{tabular}{cccccc}
\hline \multirow{2}{*}{$\begin{array}{c}\text { Embryo } \\
\text { Groups }\end{array}$} & \multicolumn{2}{l}{ Nucleocytoplasmic } & No. of & \multicolumn{2}{c}{ No. (\%) of Embryos Cleaving After Manipulation } \\
\cline { 4 - 5 } & Ratios & Embryos & 12 & $18 \mathrm{~h}$ & $24 \mathrm{~h}$ \\
\hline A* & $1: 2$ & 30 & $17(56.7)$ & $22(73.7)$ & $24(80.0)$ \\
B** & $1: 4$ & 48 & $32(66.7)$ & $42(88.9)$ & $43(89.6)$ \\
\hline
\end{tabular}

*Fused late 2-cell stage embryos with one nucleus removed.

**Fused early 4-cell stage embryos with three nuclei removed. $\mathrm{P}>0.05$. 
Table 3. The developmental abilities in vitro of the enucleated fused mouse embryos or oocytes receiving advanced embryonic nuclei

\begin{tabular}{clcccccc}
\hline & Recipient & Donor & \multirow{2}{*}{ No. of } & \multicolumn{2}{c}{ No. (\%) In Vitro Reconstituted Embryos Developed to } \\
\cline { 6 - 8 } Group & Cytoplasm & Nucleus & Embryos & 2-cell & 4-cell & 8-cell & morula \\
\hline C & La En Fu 2-cell & 4-cell & 75 & $67(89.3)$ & $57(76.0)$ & $36(48.0)$ & $24(32.0)$ \\
D & La En Fu 2-cell & 8-cell & 47 & $43(91.5)$ & $33(70.2)$ & $4(8.5)$ & 0 \\
E & En Fu 2-cell & morula & 45 & $34(75.6)$ & $10(22.2)$ & 0 & 0 \\
F & En Fu 4-cell & 8-cell & 28 & $24(85.7)$ & $18(64.3)$ & $8(28.6)$ & 0 \\
G & En oocyte & 2-cell & 61 & $27(44.3)$ & $12(19.7)$ & $3(4.9)$ & 0 \\
H & En oocyte & 8-cell & 46 & $3(6.5)$ & 0 & 0 & 0 \\
\hline
\end{tabular}

Key: En, Enucleated; La, Late; Fu, Fused.

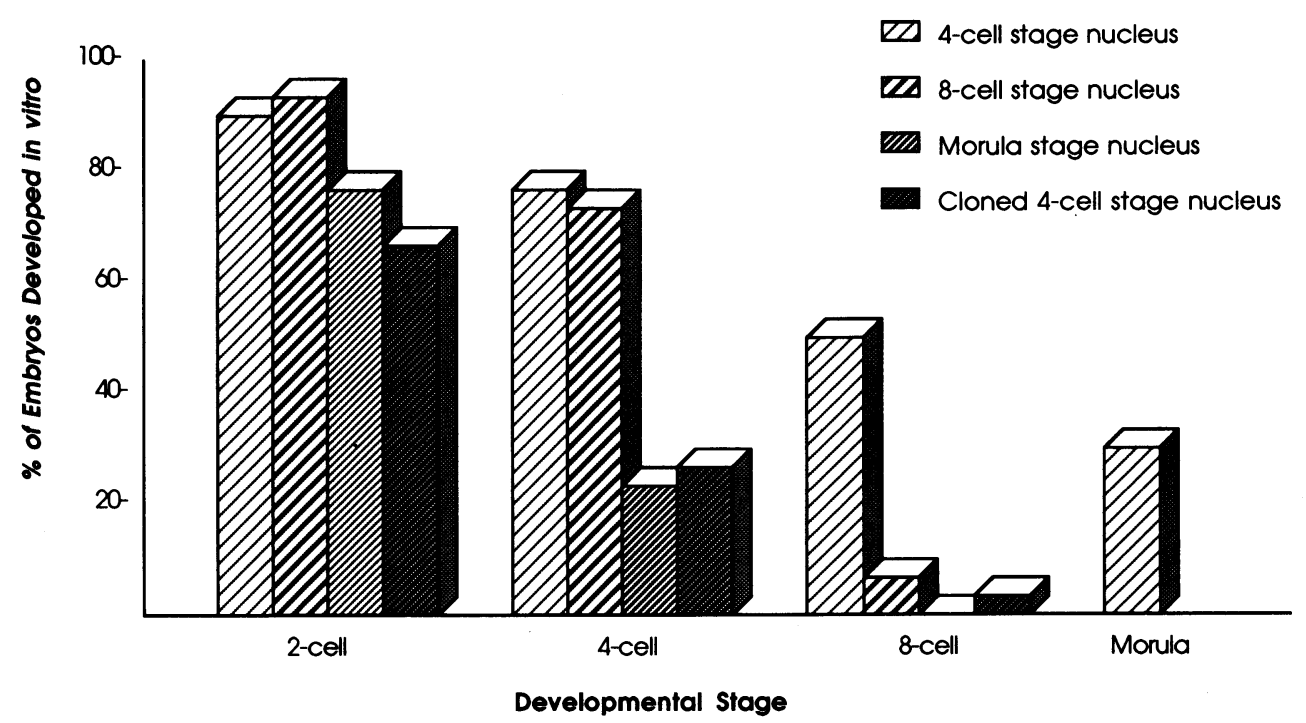

Fig. 1. The development in vitro of the reconstituted embryos following the nuclear transfer from the blastomeres of normal 4-cell, 8-cell embryos, morulae and the cloned 4-cell embryos to the cytoplasm of the enucleated and fused blastomere of 2-cell embryos. In the reconstituted embryos, the developmental ability was significantly reduced $(\mathrm{P}<0.05)$ as the stages of donor embryos advanced. The developmental abilities of the reconstituted embryos with the nuclei of morulae and those with the nuclei of the cloned 4-cell embryos were similar $(\mathrm{P}>0.05)$.

from different cell cycles (4-cell, 8-cell, and morula stages) into the cytoplasm of enucleated fused 2-cell stage embryos.

In the results showin in Fig. 1, the embryos were reconstituted by fusing blastomeres at the 3rd (4-cell stage), the 4th (8-cell stage), and the 5th (morula stage) cell cycles with the late stage cytoplast of enucleated fused 2-cell embryos.

Between Groups C, D, and E, the proportions of reconstituted embryos at different developmental stages were significantly different $(\mathrm{P}<0.05)$ according to the different stages of the transplanted donor nuclei (Table 3). The developmental abilities decreased as the age of the donor nucleus increased (Table 3, Fig. 1).

Cytoplasms of fused late 2-cell stage embryos were used to receive the nuclei of the early 4-cell stage. From these transplantations 67 reconstituted embryos were transferred to the oviducts of 5 pseudopregnant recipients on Day 1. Two of five recipients $(40 \%)$ became pregnant and 6 live young $(8.96 \%)$ were born. The eyes of all offspring were pigmented, demonstrating that the offspring were derived entirely from the transplanted embryos.

The influence of the cytoplasm at different cell cycles on the donor nuclei of the 4th cell cycle (8-cell stage) was studied by transferring the nuclei 
of an 8-cell stage embryo into the cytoplasms of the 1 st cell cycle (oocyte) (Group H), the fused 2 nd cell cycle (2-cell stage) (Group D), and the fused 3rd cell cycle (4-cell stage) (Group F). No significant differences in developmental ability in vitro were found between Group D and Group F (P>0.05). It was apparent that the cytoplasms from both the fused 2nd cell cycle (2-cell) and the fused 3rd cell cycle (4-cell) were similar in supporting the donor nuclei of the 3rd cell cycle (8-cell) to develop in vitro. However, when the cytoplasms of enucleated metaphase II oocytes received the nuclei of 8-cell stage embryos, these reconstituted embryos developed very poorly with only $6.5 \%$ (3/46) cleaving once. Compared with Group D and Group F, Group $\mathrm{H}$ developed more poorly $(\mathrm{P}<0.05)$ (Fig. 2). Likewise, the nuclei of 2-cell embryos transferred to the cytoplasm of the enucleated metaphase II oocytes (Group G) showed lower developmental ability than when transferred to the cytoplasm of enucleated fused 2-cell stage embryos $(\mathrm{P}<0.05)$ (Fig. 3).

In order to shorten the "gap" and improve functional compatibility between donor nucleus and recipient cytoplasm, nuclei in the initial stage of 2-cell, 4-cell, and 8-cell embryos were introduced into enucleated cytoplasms of oocytes, fused 2-cells, and fused 4-cells, respectively (Group G, C, and $\mathrm{F}$ ). The percent cleavage of the reconstituted embryos in Group $G$ is much lower than that in Groups C and F (Fig. 4). Even the cytoplasms from enucleated, fused 2-cell and 4-cell embryos support donor nuclei to development in vitro to a similar degree. The disparity in differentiation states between the donor nuclei of 4-cell and 8-cell stages causes the reconstituted embryos in Group $\mathrm{C}$ to cleave more than those in Group F. The greatest functional compatibility between the cytoplasm from enucleated, fused 2-cell blastomeres and the nucleus of the 4-cell stage embryo is shown in Groups $\mathrm{C}, \mathrm{F}$, and $\mathrm{G}$.

In the reconstituted embryos of Groups A-F, the advanced embryonic nuclei were transferred into the cytoplasms of enucleated fused 2-cell or 4-cell embryos. In the majority of cases, compaction occurred at the "4-cell" stage and some even at the "2-cell" stage of the reconstituted embryos. Compaction occurred earlier than in normal mouse embryos, suggesting that advanced embryonic nuclei had not been reprogrammed by the younger cytoplasm but instead the nuclei accelerated the differentiation of the cytoplasm to the compaction stage of development.

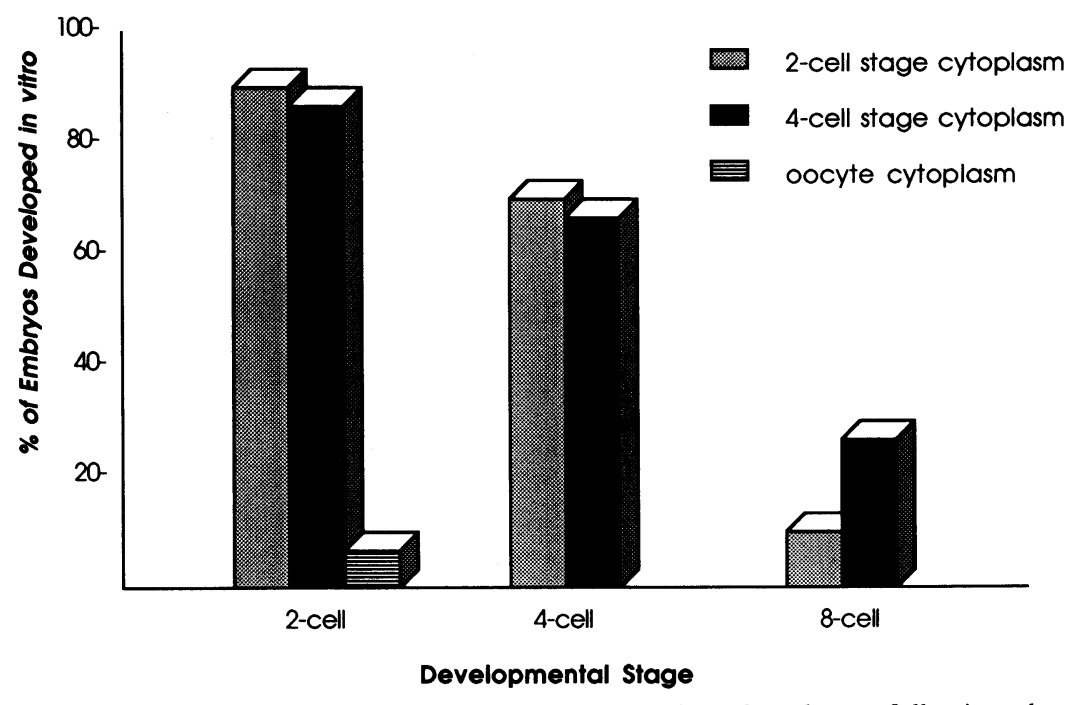

Fig. 2. The development in vitro of the reconstituted embryos following the nuclear transfer from 8-cell embryos to the cytoplasm of enucleated metaphase II oocytes, enucleated-fused blastomeres of 2-cell and 4-cell embryos. The cytoplasm of the enucleated-fused blastomeres of 2-cell and 4-cell embryos were similar in their abilities to support the development of the transferred nuclei of 8 -cell embryos $(\mathrm{P}<0.05)$. The cytoplasm of enucleated metaphase II oocytes, on the other hand, was significantly less favorable $(\mathrm{P}<0.05)$ for the development of the transferred nuclei than those of the enucleated-fused blastomeres. 


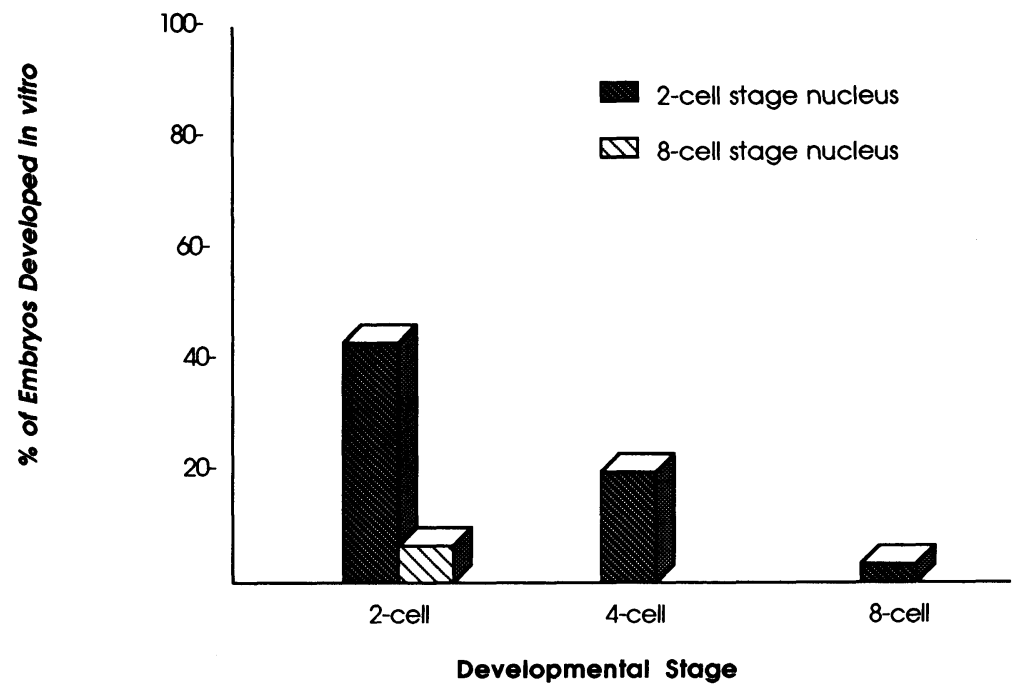

Fig. 3. The development in vitro of the reconstituted embryos following the transfer of nuclei from the blastomeres of 2-cell and 8-cell embryos to the cytoplasm of enucleated metaphase II oocytes. There was a significant difference $(\mathrm{P}<0.05)$ in the developmental abilities between the reconstituted embryos with the nucleus from the 2-cell stage embryo and those with the nucleus from the 8-cell embryo.

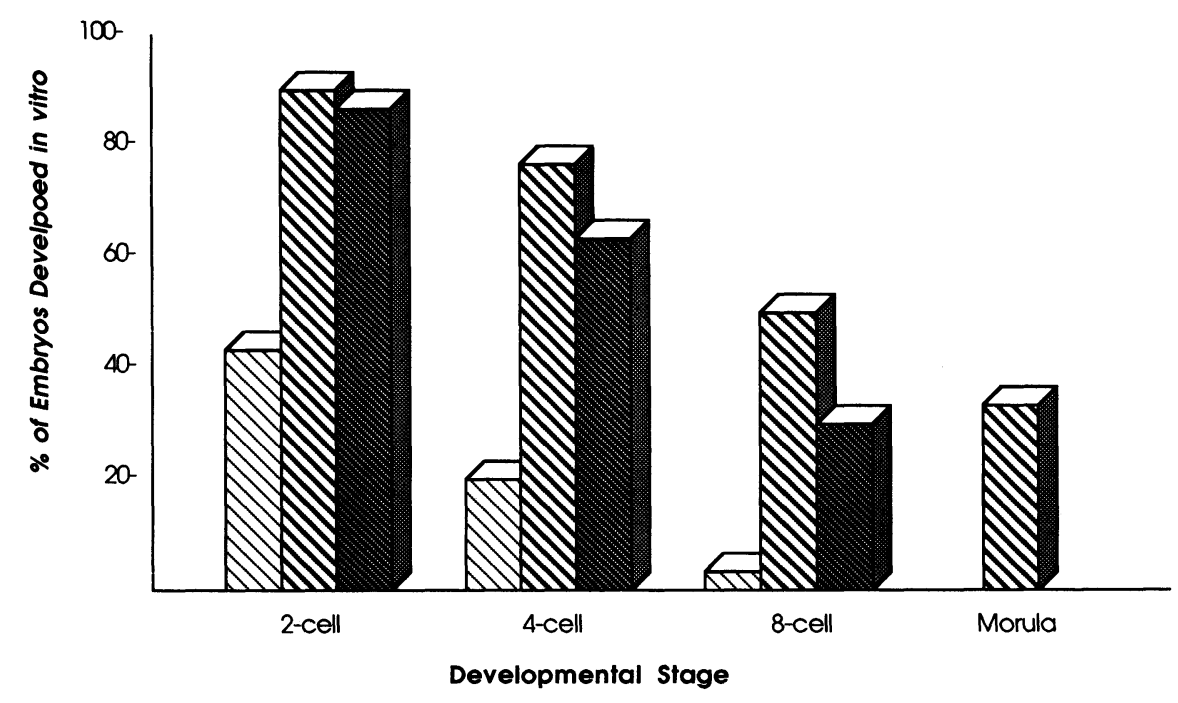

Early 2-cell nucleus was transferred into the cytoplasm of metaphase $\|$ oocyte

W Early 4-cell nucleus was transferred into the cytoplasm of enucleated, fused late 2-cell embryo

Early 8-cell nucleus was transferred into the cytoplasm of enucleated, fused late 4-cell embryo

Fig. 4. The nuclei of the blastomeres in the initial stage of 2-cell, 4-cell and 8-cell stages were transferred to the cytoplasm of enucleated metaphase II oocytes, enucleatedfused blastomeres of late 2-cell and late 4-cell stages. The experiments were carried out to shorten the gap and improve the functional compatibility between the donor nuclei and the recipient cytoplasm. The greatest functional compatibility was observed in the reconstituted embryos that had cytoplasm from the late enucleatedfused 2-cell embryos and the nucleus from the blastomere of 4-cell embryo. The developmental abilities were significantly different $(\mathrm{P}<0.05)$ among the three different combinations examined. 


\section{Experiment 3: Recloning cloned embryos}

The genomes of all the nuclei of early mouse embryos are generally thought to be identical. Nuclear transplantation may provide a method for making a large number of equally totipotent nuclei. However blastomeres lose their totipotency step by step during cleavage. A large number of equivalent blastomeres containing identical nuclei is desirable.

In this experiment, 4-cell stage embryos were collected and the individual blastomeres isolated to provide nuclei for transfer into the cytoplasms of enucleated fused 2-cell stage embryos. When these reconstituted embryos developed into 4-cell stage embryos, the blastomeres were again isolated and were used to provide donor nuclei for transfer. The above process was repeated. The number of embryos at each successive step in this nuclear transplantation schedule is summarized in Table 4.

One hundred twelve blastomeres (112/124, $90.32 \%)$ were isolated from the 31 embryos (124 blastomeres) derived from nuclear transplantation. One hundred (100/112, 89.29\%) embryos were produced by micromanipulation. After electrofusion, $94(94 / 100,94 \%)$ recloned embryos were obtained.

The development of recloned embryos in vitro and in vivo is shown in Table 5 and in Table 6. Fifty-three recloned embryos were cultured in vitro; $36(67.92 \%), 15(28.30 \%)$ and $1(1.75 \%)$ of them developed into 2-cell, 4-cell, and 8-cell embryos, respectively, Meanwhile, 41 recloned embryos were transferred into day-1 pseudopregnant recipients, and $17(41.46 \%)$ were collected on day 3 . Four $(4 / 17,23.53 \%)$ of the collected recloned embryos developed to the morula stage and one $(1 / 17,5.88 \%)$ to the early blastocyst stage.

The cleavage rates in vitro of recloned embryos were significantly different from those of the reconstituted embryos resulting from transferring the nuclei of 4-cell normal embryos to the cytoplasms of enucleated fused 2-cell stage embryos (Group C) $(\mathrm{P}<0.05)$. However, no significant

Table 4. Number of embryos at each successive step in nuclear transplantation

\begin{tabular}{ccccc}
\hline Group & $\begin{array}{c}\text { No. (\%) Cloned Embryos Developing } \\
\text { from First Transplantation }\end{array}$ & $\begin{array}{l}\text { No. (\%) of Isolated } \\
\text { Blastomeres Used }\end{array}$ & $\begin{array}{l}\text { No. (\%) of Embryos After } \\
\text { Micromanipulation }\end{array}$ & $\begin{array}{l}\text { No. (\%) Surviving } \\
\text { Electrofusion Step }\end{array}$ \\
\hline 1 & $3(75.00)$ & $11(91.67)$ & $10(90.91)$ & $9(90.00)$ \\
2 & $3(75.00)$ & $11(91.67)$ & $9(81.82)$ & $9(100.00)$ \\
3 & $3(75.00)$ & $9(75.00)$ & $8(88.89)$ & $4(50.00)$ \\
4 & $4(100.00)$ & $15(93.75)$ & $14(93.33)$ & $14(100.00)$ \\
5 & $3(75.00)$ & $12(100.00)$ & $11(91.67)$ & $11(100.00)$ \\
6 & $3(75.00)$ & $9(75.00)$ & $6(66.67)$ & $6(100.00)$ \\
7 & $5^{*}$ & $20(100.00)$ & $19(95.00)$ & $18(94.74)$ \\
8 & $7 *$ & $25(89.29)$ & $23(92.00)$ & $23(100.00)$ \\
Total & 31 & $112(90.32)$ & $100(89.29)$ & $94(94.00)$ \\
\hline
\end{tabular}

All recipients were fused enucleated late 2-cell cytoplasms. Each nuclear transplantation was from a single 4-cell embryo except $(*)$ entries that included several donor embryos.

Table 5. The development of recloned embryos in vitro

\begin{tabular}{ccccc}
\hline & & \multicolumn{3}{c}{ No. (\%) Developed to in vitro } \\
\cline { 3 - 5 } Group & No. of Recloned Embryos & 2-cell & 4-cell & 8-cell \\
\hline 1 & 9 & $8(88.89)$ & $3(33.33)$ & $1(11.11)$ \\
2 & 9 & $7(77.78)$ & $4(44.44)$ & 0 \\
3 & 4 & $3(75.00)$ & $1(25.00)$ & 0 \\
4 & 14 & $10(71.43)$ & $6(42.86)$ & 0 \\
5 & 11 & $5(45.45)$ & $1(9.09)$ & 0 \\
6 & 6 & $3(50.00)$ & 0 & 0 \\
\hline Total & 53 & $36(67.92)$ & $15(28.30)$ & $1(1.75)$ \\
\hline
\end{tabular}


Table 6. The development of recloned embryos in vivo.

\begin{tabular}{ccccc}
\hline & No. of Recloned Embryos & No. (\%) of & \multicolumn{2}{c}{ No. (\%) developed to } \\
\cline { 3 - 4 } Group & Transferred to Recipient & Recollected Embryos & Morula & Early Blastocyst \\
\hline 7 & 18 & $10(55.56)$ & 3 & 0 \\
8 & 23 & $7(30.43)$ & 1 & 1 \\
\hline Total & 41 & $17(41.46)$ & $4(23.534 / 17)$ & $1(5.881 / 17)$ \\
\hline
\end{tabular}

difference was found in the cleavage rates between the recloned embryos and the reconstituted embryos derived from transferring the nuclei of normal morulae into the cytoplasms of enucleated fused 2-cell embryos (Group E) ( $\mathrm{P}>0.05$ ) (Fig. 1). Even though the donor nuclei used for recloning came from the "4-cell" stage of the cloned embryos, these nuclei were themselves at the 5 th cell cycle, the same as for the nuclei of the normal morulae stage. These results with recloned embryos indicated that the nuclei at the 5 th cell cycle reflected a series of subtle but significant structural modifications so that they could not be reprogrammed by repeated transfer into the cytoplasms of enucleated fused 2-cell stage embryos.

\section{Discussion}

Changing the nucleocytoplasmic ratio by increasing the amount of cytoplasm reduced the rate of embryonic development. The reasons for this decline in the rate of development are not known, but general demand to the structure of the egg required by nuclear removal may not be repaired quickly. However, stage specific protein synthesis remains the same [20] even though overall development is slower. Certain developmental events such as compaction of blastomeres can occur earlier than in normal embryos even in the retarded experimental embryos. Thus protein synthesis, and many other events in development, must be independent of the nucleocytoplasmic ratio. However, a certain concentration of products produced by nuclear activity [21] may be required in order for certain steps in development to occur. Borsuk and Manka [4] reported that the formation of a male pronucleus was accelerated when the amount of the oocyte cytoplasm was decreased. So by increasing the cytoplasmic con- tent per nucleus, the time required to accumulate the necessary amount of transcripts would become longer, but such a putative process does not affect embryo compaction.

Advanced embryonic nuclei at different stages of development were transferred in these experiments into enucleated fused 2-cell embryos. The results showed that a decreasing percentage of normal development followed the use of nuclei of increasing ages of development. When the nuclei from 4-cell, 8-cell, and morula embryos were transferred into enucleated fused 2-cell embryos, $48.0 \%, 8.5 \%$ and $0.0 \%$ of them developed to the 8 -cell stage, respectively. This decrease in development after asynchronous transfer is possibly due to the failure of the donor nuclei to respond to the pattern of regulatory signals from the surrounding recipient cytoplasm $[22,23]$ in which new polypeptides may be synthesized continuously. Tsunoda [13] previously reported improved development when the embryos used for donor nuclei were stored at a low temperature $4-10 \mathrm{~h}$ prior to use. However, in our experiments donor nuclei were treated differently. We transplanted the nuclei of the early 4-cell embryo into a doubled amount of cytoplasm without delay instead of storing the donor embryos at a lower temperature. However, whether the low nucleocytoplasmic ratio affects the donor nuclei in the same way as the cold treatment of donor nuclei cannot be determined except by additional experiments.

The influence of recipient cytoplasm on nuclei was tested by transferring the nuclei of the 8-cell stage nuclei into the cytoplasm of enucleated fused 2-cell, 4-cell, and metaphase II oocytes. The cytoplasms of the 2-cell and 4-cell stages supported normal development but the cytoplasm of the oocytes did not. By contrast in a high proportion of enucleated metaphase II oocytes that received nuclei from sheep [24], cattle [25], and rabbits [26] the 8-cell stage embryos developed to the morula 
or blastocyst stage in vitro and offspring were obtained after transferring the embryos to recipient females. Tsunoda proposed that a likely reason for these results is the difference in the time of embryonic genome activation among these species. The genome is activated at the 2-cell stage in the mouse [27] and the goat [28]; at the 8-16 cell stage in the sheep [29] and the cow [30]; and at the 16-cell stage in the rabbit [31]. The "maturation promoting factor" [32] activity is high in the cytoplasm of the second metaphase oocyte. Those types of cytoplasms receiving transplanted nuclei from embryos before embryonic genome activation will develop in vitro and in vivo; and after genome activation, they may not develop [33]. In cattle [25] and sheep [29] nuclear transplantation experiments using the second metaphase oocyte as the recipient showed no difference in development between pretranscriptional and posttranscriptional activation stages. These results suggest that transcriptional activation alone does not necessarily cause irreversible modification of the genome. At least some nuclei in some species appear to be successfully reprogrammed after reaching the embryonic genome activation stage. Then why does the cytoplasm of the mouse oocyte not reprogram the donor nucleus? How does the mouse differ from the other species? For the male pronucleus to form properly after fertilization, material from the germinal vesicle of the imma- ture oocyte must be present [34, 35]. These cytoplasmic components such as "maturation promoting factor" are only present in the oocytes [32], and they may be dispersed and used up in the cytoplasm during mitosis.

The interaction of nucleus and cytoplasm is of course quite complicated. Specialized thymocyte nuclei, e.g., when transferred into the oocyte close to the time of activation produced complete nuclear remodeling that is, the nuclear envelope breaksdown, condensation of chromatin occurs, and then reconstitution of the nuclear envelope and formation of pronucleus-like nucleoli occurs $[36,37,38]$. In contrast when the totipotent nuclei of the 8-cell stage mouse embryos were transferred into the cytoplasms of oocytes from which chromosomes had been removed, there was no complete nuclear remodeling [111]. On the other hand, when the nuclei of an 8-cell mouse embryo were transferred into enucleated oocytes of rabbits, the reconstituted hybrid embryos did develop to the blastocyst stage in vitro (Du et al. 1991, personal communication). This experiment demonstrated that no irreversible changes had occurred in the nuclei of the 8-cell mouse embryos. The exposure time of the nucleus to younger cytoplasm was extended by recloning of the nuclei, but no identifiable change occurred in the developmental capacity of the transferred and recloned nuclei.

\section{References}

1. Rott NN, Shevela GA. Changes in the rate cell divisions in the course of early development of diploid and haploid loach embryos. J Embryol Exp Morphol 1968; 20: 141-150.

2. Newport J, Kirschner M. A major developmental transition in early Xenopus embryo: I. Characterization and timing of cellular changes at the midblastula stage. Cell 1982; 30: 675-686.

3. Petzoldt U, Muggleton-Harris A. The effect of the nucleocytoplasmic ratio on protein synthesis and expression of a stage-specific antigen in early cleaving mouse embryos. Development 1987; 99: 481-491.

4. Borsuk E, Manka R. Behavior of sperm nuclei in intact and bisected metaphase II mouse oocytes fertilized in the presence of colcemid. Gamete Res 1988; 20: 365-376.

5. McGrath J, Solter D. Nucleocytoplasmic interaction in the mouse embryo. J Embryol Exp Morphol
1986; 97: 277-289 (Suppl).

6. Evsikov V, Morozoval M, Solomko AP. The role of the nucleocytoplasmic ratio in development regulation of the early mouse embryo. Development 1990; 109: 323-328.

7. Surani MA, Barton SC, Norris ML. Nuclear transplantation in the mouse: heritable differences between parental genomes after activation of the embryonic genome. Cell 1986; 45: 127-136.

8. Stice SL, Robl JM. Nuclear reprogramming in nuclear transplanted rabbit embryos. Biol Reprod 1988; 39: 657-664.

9. Howlett S, Barton SC, Surani MA. Nuclear cytoplasmic interactions following nuclear transplantation in mouse embryos. Development 1987; 101: 915-923.

10. Howlett S, Barton SC, Norris ML, Surani MA. Nuclear and cytoplasmic locatilization of new synthesized protein in the early mouse embryos. 
Development 1988; 103: 129-134.

11. Barnes FL, Robl JM, First NL. Nuclear transplantation in mouse embryos: Assessment of nuclear function. Biol Reprod 1987; 36: 1267-1274.

12. Robl JM, Gilligan B, Critser ES, First NL. Nuclear transplantation in mouse embryos: Assessment of recipient cell stage. Biol Reprod 1986; 34: 733-739.

13. Tsunoda Y, Yasui T, Shioda Y, Nakamura K, Uchida T, Sugie T. Full-term development of mouse blastomere nuclei transplanted into enucleated two-cell embryos. J Exp Zool 1987; 242: $147-151$.

14. Kono T, Tsunoda Y, Nakahara T. Production of identical twin and triplet mice by nuclear transplantation. J Exp Zool 1991; 257: 214-219.

15. Anderegg C, Markert CL. Successful rescue of microsurgically produced homozygous uniparental mouse embryos via production of aggregation chimeras. Proc Natl Acad Sci USA 1986; 83: 6509-6513.

16. Zimmerman U, Vienken J. Electric field-induced cell-to-cell fusion. J Membr Biol 1982; 67: 165-182.

17. Onodera M, Tsunoda Y. Parthenogenetic activation of mouse and rabbit eggs by electric stimulation in vitro. Gamete Res 1989; 22: 277-283.

18. Markert CL, Petters RM. Homozygous mouse embryos produced by microsurgery. $J$ Exp Zool 1977; 201: 295-302.

19. McGrath J, Solter D. Nuclear transplantation in mouse embryo by microsurgery and cell fusion. Science 1982; 220: 1300-1303.

20. Kidder GM, Mclachlin JR. Timing of transcription and protein synthesis underlying morphogenesis in preimplantation mouse embryos. Dev Biol 1985; 112: 265-275.

21. Johnson MH. The molecular and cellular basis of preimplantation mouse development. Biol Rev 1981; 56: 463-498.

22. Ege T, Ringertz NR. Viability of cellsreconstituted by virus-induced fusion of minicells with anucleate cells. Expl Cell Res 1975; 94: 469-473.

23. Levinson $\mathbf{J}$, Goodfellow $\mathbf{P}$, Vadeboncoeur $\mathbf{M}$, McDewitt H. Identification of stage-specific polypeptides synthesized during mueine preimplantation development. Proc Natl Acad Sci USA 1978; 75: 3332-3336.

24. Willadsen SM. Nuclear transplantation in sheep embryos. Nature 1986; 320: 63-65.

25. Prather RS, Barnes FL, Sims ML, Robl JM, Eyestone WH, First NL. Nuclear transfer in the bovine embryo: Assessment of donor nuclei and recipient oocyte. Biol Reprod 1987; 37: 859-866.

26. Smith LC, Wilmut T. Influence of nuclear and cytoplasmic activity on the development in vivo of sheep embryos after nuclear transplantation. Biol Reprod 1989; 40: 1027-1035.

27. Bolton VN, Oades PJ, Johnson MH. The relationship between cleavage DNA replication and gene expression in the mouse 2-cell embryo. $J$ Embryol Exp Morphol 1984; 79: 139-163.

28. Chartrain I, Nair A, King WA, Picard L, St-Pierre H. Nucleoli and nucleolus organizer regions (NORs) in early embryos. Theriogenology 1986; 25: 145.

29. Crosby IM, Gandolfi F, Moor RM. Control of proteins synthesized during early cleavage of sheep embryos. J Reprod Fertil 1988; 82: 769-775.

30. King WA, Nair A, Betteridge KJ. The nucleolus organizer regions of early bovine embryos. J Dairy Sci 1985; 68: 249 (Suppl).

31. Manes C. The participation of the embryonic genome during early cleavage in the rabbit. Dev Biol 1973; 32: 453-459.

32. Masui Y, Markert CL. Cytoplasmic control of nuclear behavior during meiotic maturation of frog oocytes. J Exp Zool 1971; 177: 129-146.

33. Tsunoda $\mathbf{Y}$, Tokunaga $\mathbf{T}$, Imai $\mathbf{H}$, Uchida $\mathbf{T}$. Nuclear transplantation of male primordial germ cells in the mouse. Development 1989; 107: 107-411.

34. Tarkowski AK, Balakier H. Nucleo-cytoplasmic interactions in cell hybrids between mouse oocyte, blastomeres and somatic cells. J Embryol Exp Morphol 1982; 55: 319-330.

35. Tarkowski AK. Nucleo-cytoplasmic interactions in oogenesis and early embryogenesis in the mouse. In: Burger MM, Liss NR, Weber R (eds). Embryonic Development. Part A: Genetic Aspects. New York: Alan R. Liss, Inc; 1982: 407-416.

36. Czolowska R, Modlinski JA, Tarkowski AK. Behavior of thymocyte nuclei in nonactivated and activated mouse oocytes. J Cell Sci 1984; 69: 19-34.

37. Szollosi D, Czolowska R, Soltynska MS, Tarkowski AK. Remodeling of thymocyte nuclei in activated mouse oocytes: an ultrastructural study. Eur J Cell Biol 1986; 42: 140-151.

38. Szollosi D, Czolowska R, Soltynska MS, Tarkowski AK. Remodeling of mouse thymocyte nuclei depends on the time of their transfer into activated homologous oocytes. J Cell Sci 1988; 91: 603-613. 